\title{
Cereal Storage Techniques: A Review
}

\author{
Hatice Pekmez \\ Naci Topçuoğlu Vocational School, University of Gaziantep, Gaziantep 27000, Turkey
}

\begin{abstract}
Cereal grains are stored to preserve the product from storing to consuming without any quality loss. The choice of the most suitable and economical store has great importance on storage period of cereals under consideration of climate conditions, types of grain and transportation facility. The aim of present study was to give information about different cereal storage methods and discuss the most preferable technique for stock keepers. There are five main storage methods for the cereals, i.e., bulk storage, storage in underground pit, storage in bags, storage in sheds and storage in silos. Each has many advantages and disadvantages. Grains are usually preserved as bulk stack in horizontal stores. Nowadays, the storage underground is not preferred in cereal industry. For long-term storage period, cereals are unfavorable when stored as bulk in bags. Location, moisture content and sufficient ventilation are important factors for cereals stored in sheds. The most preferred storage technique in plants is to keep the products in silos. Steel and galvanized silos are the most common ones when compared with the others. In recent years, convention of storage techniques for grains has been advanced with the innovations, such as aeration, refrigerated storage, modified atmospheric storage and hermetic storage systems.
\end{abstract}

Key words: Storage of cereals, bulk, underground, bag, shed, silo.

\section{Introduction}

Cereal grains, such as wheat, corn, rye, oat, rice, etc., are important nutritional and energy sources for humans. They must be stored, transported and conveyed using methods that preserve their quality. Storage varies with the length of time ranging from short-term storage on farm for drying to long-term storage for strategic reserves. That is, storage can occur on farm or at large commercial facilities [1]. Loss in stored grains is nearly $20 \%$ of the whole production due to population increase globally, a huge demand for the cereals and improper storage conditions $[2,3]$.

Microbial, pest, enzymatic activities, mechanical effects, foreign matter damages and heat problems, which result in quality loss in grains during storage, can be prevented by right storage methods using proper machine and equipment [4]. Up to today, many storage methods have been used for ages. However traditional or modern method, the aim of storing grain

Corresponding author: Hatice Pekmez, assistant professor, research fields: cereal technology, starch properties, ozonation, and drying technology. is to protect the quality of grains, prevent grain losses and conserve the product in a proper way [2].

Post-harvest loss caused by climatic region, country, crop, infrastructure and methods of storage is a major problem for cereal safety. Safe grain harvest and storage play a crucial role to prevent losses caused mainly by weevils, beetles, moths and rodents [5]. Before storage of cereals, there are many protectional points from damages, such as harvesting of crops on time, drying of crops on farm without waiting, setting of new and old crops separately, cleaning of crops from foreign materials, careful selection of storage site, storage structure and suitable fumigation of empty store.

During storage period, proper aeration of grains, regular inspection of grain stock, cleaning and fumigation of stored grains need to be performed, because these requirements have great importance on the safe and scientific storage [5]. The store chosen appropriately must satisfy the grain to be kept dry, kept at a uniform temperature and protected from insect, rodents and birds [6]. There are many researches and applications for storage of cereals. 
Nowadays, new technology development in this area has been providing easier control of store, more effectiveness for stored grains and more stable conditions during storage period. The present article is the review of the different cereal storage techniques and structures, the newly developed methods, their advantages and disadvantages during storage period and discussion about preferable types by stock keepers.

\section{Main Storage Techniques}

The grain production has increased all over the world over last decades, as the grain is the essential consumer goods for human and modulating economy. That is, grain production is the key part of the economic and social development. A grain stored properly must be equivalent to a grain produced. During storage, significantly qualitative and quantitative losses occur due to several factors, such as environmental factors (temperature, moisture content of grains, $\mathrm{pH}$, humidity, etc), type of storage structure used, length and purpose of storage, method of storing grains, and biological factors (insects, pests, microorganisms and rodents). Nowadays, the grains are stored using the improved methods, such as in bags, silos, sheds, containers and even in piles on the ground managed as man-made ecosystems [3].

Traditionally, there are two approaches employed for grain storage: temporary storage and long-term storage methods [5].

Under temporary storage, aerial storage, storage on the ground or on drying floors and open timber platforms which is normally done at farm level, are followed, whereas under long term storage methods, storage baskets (cribs) made exclusively of plant materials, calabashes, gourds, earthenware pots, jars, solid wall bins, and underground storage can be employed [5].

Modernly, warehouses are scientific storage structures especially constructed for the protection of the quantity and quality of stored products. Under bulk storage, sealing and aeration play an important role. Aeration may be ambient or refrigerated on base of the requirement. Thus, improved storage structures and scientific storage of grains in form of warehouses are the need of the hour to strengthen traditional means of storage with modern inputs and to provide cheaper storage facility to farmers as well as to prevent enormous storage losses [5].

As traditional or modern, there are five main storage methods for the cereals, i.e., bulk storage, storage in underground pit, storage in sack, storage in warehouse and storage in silo. Each has many advantages and disadvantages during storage period of grains.

\subsection{Bulk Storage}

Grains can be stored and preserved as bulk in both vertical and horizontal warehouses [7]. In this method, the surface of bulk stack cereals (wheat, barley, rye, oat, corn, chickpea and lentil) is levelled properly. It is possible to store more grain on unit area. It also facilitates the control of grain samples easily, has less labor cost and provides the time-saving.

\subsection{Storage Underground}

Underground pits are claimed to keep grain without damage for many years. The pits keep grain cool, and some of them are relatively airtight. Grain on top and around the sides can however often be mouldy [8]. In this method, hay, stalk, polyethylene, apron, etc., are placed both under and also on the cereal before covering with soil. This technique provides the grain not to contact with air, i.e., oxygen $\left(\mathrm{O}_{2}\right)$ during storage period. However, the weather conditions and the position of ground should be considered carefully not to be exposed to any damage on cereals. Nowadays, the storage underground is not preferred in the cereal industry.

\subsection{Storage in Bag}

For long-term storage period, some types of cereals 
(rice, flour, legume, etc.) are unfavorable for bulk storage, so they are put into bags (sacks) for keeping quality. The moisture content of cereal is the critical factor on this technique. If the moisture content in cereal is increased, the number of sacks in cereal stock is decreased. In this method, it is easy to number the sacks and to take sample from each sack, but it is difficult to control the products as they are in bags. Besides, less amount of cereals are stored on unit area when compared to the bulk storage technique. This method is also more expensive due to high labor cost and more time-consuming causing to easier rodent damages.

\subsection{Storage in Warehouse (Shed)}

Sheds are commonly used by bulk handling companies, but require careful site preparation, labour for handling large tarp covers and machinery to move grain on and off the grain stack. Effective treatment of insect infestation is difficult in sheds and bunkers. For on-farm storage, grain in bags may be a more suitable short-term alternative [9]. For the storage in warehouse, the determination of location, control of moisture content and supplement of sufficient aeration of cereals are important factors. The cereal and cereal products could be stored as bulk stack and also in sacks in this technique. The damage from insects is the most common problem in warehouses.

\subsection{Storage in Silo}

The most preferred storage technique in plants is to store the grain in silos. It has many advantages due to less labour cost and less time-consuming depending on easy discharge and conveying of cereals and keeping hygienic conditions during these processes. As the silos are vertical, more products are stored on the unit area. There are three types of silos made of wood, concrete and steel. Wood silos are not suitable for preservation, as they are susceptible to fire and favorable for the insect surviving. Concrete silos are ideal to store cereals, as they are required less labor cost and less time for storage. Steel silos (Fig. 1) [10] and galvanized silos are the most common used stores, because they are more resistant and easier controlled when compared with the others. Wheat, barley, rye, oat, etc., could be stored conveniently both in concrete and steel silos.

\section{Advanced Storage Methods}

Storage technologies for grains have been advanced with innovations on the main systems, such as aeration, refrigerated storage, modified atmospheric storage, hermetic storage systems in many developed countries [3].

\subsection{Grain Aeration}

The most common non-chemical alternative for storage of cereals is the use of aeration systems during the winter [11]. Aeration is supplied by the forced movement of ambient air of suitable quality, or suitably conditioned air, through a grain bulk for improvement of grain storage. It is an acceptable practice to reduce the commodity temperature and is achieved by using mechanical aeration by means of fans. This system is suitable especially for low humid environment. On commercial scale, forced aeration plays important and effective role to preserve grains [3].

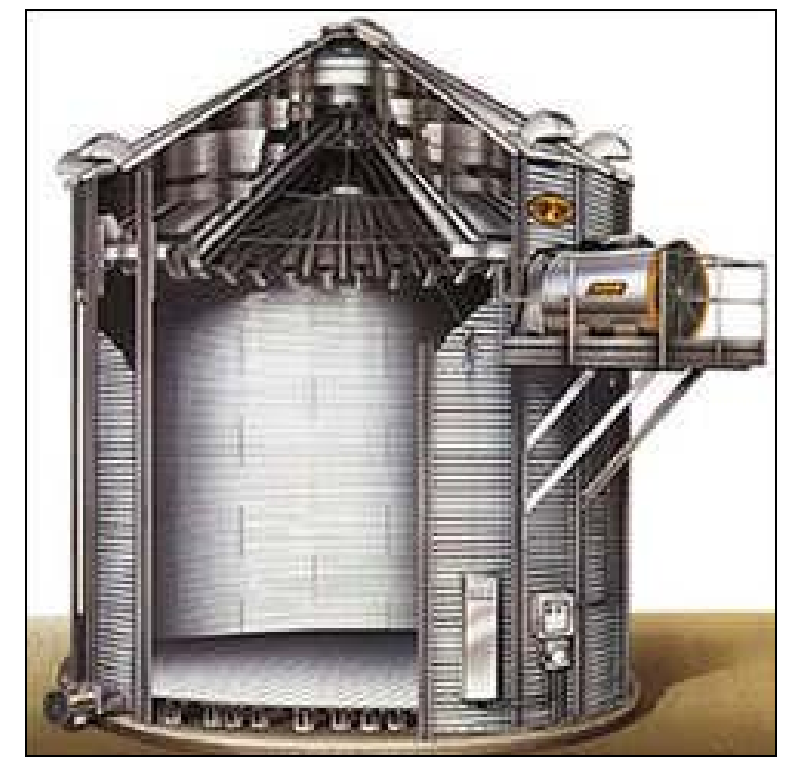

Fig. 1 Inside of steel silo [10]. 
In the study of silo automation control system with fuzzy logic controller, the grain can be stored at appropriate temperature and humidity [12].

\subsection{Refrigerated Storage}

The main objective of refrigerated aeration in the summer time is to achieve temperatures of less than $18{ }^{\circ} \mathrm{C}$ to reduce insect activity [11]. In this method, ambient air is cooled and then passed over the bulk grains via existing aeration system. The initial investment for refrigerated storage system is comparatively higher, but together with the dehumidified air method, it could provide answers to the practicability of aeration for safe commercial storage in tropical climates [3]. In this way, cold centered silo design has been studied [13].

\subsection{Modified Atmosphere Technology}

In warm climates, for cereal grain stored in bags or in bulk, a new gaseous application technology, modified atmospheres, has successfully replaced fumigants [11]. Modified atmosphere (MA) and controlled atmosphere (CA) treatments have been proved not only to control insects but also to preserve the quality of the commodity with no residues after treatment. They offer alternative to the use of conventional residue producing chemical fumigants for controlling insect pests attacking stored grain, oilseeds, processed commodities and some packaged foods $[3,14]$. An integrated pest management (IPM) control program could be integrated for insect monitoring, aeration in winter, chilling with refrigerated air in summer in grain silos, bio-generated MAs, for insect control and for quality [11].

\subsection{Hermetic Storage}

Hermetic storage is based on bio-generated atmospheres. The generation of oxygen-depleted and carbon dioxide-enriched interstitial atmosphere is a result of the respiration of the aerobic organisms living in the commodity [14]. The method enables insects and other aerobic organisms in the grain or the grain itself to generate the modified atmosphere by reducing $\mathrm{O}_{2}$ and increasing $\mathrm{CO}_{2}$ concentrations through respiratory metabolism. Respiration activity of the living organisms creates an atmosphere containing about $1 \%-2 \% \mathrm{O}_{2}$ and about $20 \% \mathrm{CO}_{2}$. Insect control success due to the hermetic storage treatment is comparable to conventional fumigants (over $99.9 \%$ kill), and losses due to insect activity are minimal. Low $\mathrm{O}_{2}$ and high $\mathrm{CO}_{2}$ environment kills insect and mite pests, and prevents aerobic fungi from growing [3].

\section{Conclusions}

The choice of the most suitable and economical storage method has great importance on storage period of cereals to prevent deterioration caused by physical, chemical and biological factors. In cereal industry, among the main storage methods (bulk storage, storage underground, storage in bags, storage in sheds), the most preferred storage technique is to store in silo, especially made from galvanized steel due to less labour cost, time-saving, easy discharge, storing more products on unit area, conveying of cereals under hygienic conditions during the processes and also easy transportation. When the silos are advanced with temperature, humidity, pressure control and aeration systems to maintain the constant conditions, the effectiveness and period of traditional grain storage would increase amazingly and result in demanding by stock keepers.

\section{References}

[1] Bucklin, R., Thompson, S., Montross, M., and Abdel-Hadi, A. 2013. "Grain Storage Systems Designs." In Handbook of Farm, Dairy, Food Machinery Engineering. New York, USA: Elsevier, 123-75.

[2] Miller Magazine. 2016. "Grain Storage and Healthy Storage Conditions.” Accessed August 5, 2016. http://www.millermagazine.com/english/grain-storage-an d-healthy-storage-conditions/.

[3] Said, P. P., and Pradhan, R. C. 2014. "Grain Storage Practices: A Review.” J. Grain Process. Stor. 1 (1): 1-5. 
[4] Tüfekçi, S. 2016. "Effects of Storage Systems on Grain Quality.” Miller Magazine. Accessed August 5, 2016. http://www.millermagazine.com/80/ index.html/.

[5] Mishra, A., Prabuthas, P., and Mishra, H. N. 2012. "Grain Storage: Methods and Measurements." Quality Assurance and Safety of Crops and Foods 4 (3): 136-58.

[6] Mrema, G. C., Gumbe, L. O., Chepete, H. J., and Agullo, J.O. 2011. "Grain Crop Drying, Handling and Storage." In Rural Structures in the Tropics: Design and Development. Rome, Italy: FAO, 363-411.

[7] Kemaloğlu, İ., and Baran, B. 2011. "Wheat in Milling." In Handbook of Miller. İstanbul, Turkey: Parantez, 23-47. (in Turkish)

[8] Bhardwaj, S. 2014. "Grain Storage Structures for Farmers." Pop. Kheti 2 (2): 202-5.

[9] Grains Research and Development Corporation (GRDC). 2011. "Grain Storage Facilities." Grains Industry Guide. Accessed August 5 , 2016. https://grdc.com.au/ /media/.../Grain-storage-facilities.pdf/.

[10] Ministry of Education (MEB). 2011. "Storage of Cereals." Accessed August 5, 2016. http://megep.meb.gov.tr/mte_program_modul/moduller_p df/Tahılları Depolama.pdf/. (in Turkish)

[11] Navarro, S., and Navarro, H. 2016. "Emerging Global Technological Challenges in the Reduction of Postharvest Grain Losses." In Proceedings of the 15th International Cereal and Bread Congress, 39.

[12] Fidan, U., and Satuk, S. 2011. "Designing of Silo Automation Control System with Fuzzy Logic Controller." AKU J. Sci. 11: 1-14. (in Turkish)

[13] Erbaş, M. 2016. “Cold-Centered Silo Design.” Miller Magazine. Accessed August 5, 2016. http://www.millermagazine.com/80/index.html/.

[14] Navarro, H., and Navarro, S. 2016. "Organic Treatments of Stored Cereals and Grains." In Proceedings of the 15th International Cereal and Bread Congress, 6. 